\title{
COVID-19 pandemic and surgery
}

\author{
Pandemia COVID-19 y cirugía
}

$\mathrm{T}$ hrough history there have been several pandemics that have changed humanity and the way individuals relate to each other. On March 11, 2020, the World Health Organization declared the SARS-CoV-2 pandemic, which has changed the way we live. We had to cancel scheduled surgeries, transform operating rooms, and make them available for COVID-19 positive patients. On the other hand, there were fewer staff in the wards, family visits were limited, and the way of giving reports was changed. In addition, the entire healthcare team has to provide support in COVID areas. ${ }^{1,2}$

For the time being, scheduled surgery was allowed for oncologic patients. ${ }^{2}$ Regarding truly emergency surgeries, it is recommended to operate incarcerated hernias with loop compromise, intestinal perforations, ischemia, appendectomies, acute cholecystitis with cholangitis, and anastomosis leaks. ${ }^{3}$ Among the procedures that can and should wait, there are uncomplicated intestinal occlusions, non-acute cholecystitis, and diverticular disease when it responds to medical management, to name a few. We also had to change informed consents. Now more than ever, it is essential to be very familiar with the ever-changing guidelines of the General Health Law.

Since SARS-CoV-2 is transmitted by aerosols - which is more than proven-, it is important to use personal protective equipment, keep a "healthy" distance, and always wear a face mask. We have already been doing this in surgery, but now all procedures should be handled as suspicious until proven otherwise. Even so, testing is not as sensitive or as fast as we surgeons would like. To work in that no-man's land, we must wear full protective gear. ${ }^{4,5}$

From one day to the next, teaching took a turnaround, both at undergraduate and postgraduate levels, and the same occur with teaching programs for our associates. By taking advantage of virtual resources, we have been able to continue with part of the established programs, which are in a constant adaptation.

This special issue, dedicated to SARS-CoV-2, deals with many of the problems we are already seeing. The articles contained herein will also give us a glimpse of issues to come. I highly recommend reading them.

Received: 07/01/2020 Accepted: 07/25/2020

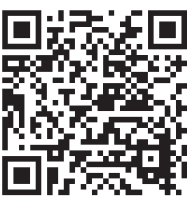

\section{REFERENCES}

1. Huremović D. Brief history of pandemics (pandemics throughout history). In: Huremović D. Psychiatry of pandemics. A mental health response to infection outbreak. Psychiatry of Pandemics. Ham, Switzerland: Springer; 2019. pp. 7-35.

2. Al-Jabir A, Kerwan A, Nicola M, et al. Impact of the Coronavirus (COVID-19) pandemic on surgical practice - Part 1. Int J Surg. 2020; 79: 168-179.

3. Al-Jabir A, Kerwan A, Nicola M, et al. Impact of the Coronavirus (COVID-19) pandemic on surgical practice - Part 2 (surgical prioritisation). Int J Surg. 2020; 79: 233-248.

How to cite: Escamilla OAC. COVID-19 pandemic and surgery. Cir Gen. 2020; 42 (2): 93-94. 
4. Chu DK, Akl EA, Duda S, et al. Physical distancing, face masks, and eye protection to prevent person-to-person transmission of SARS-CoV-2 and COVID-19: a systematic review and meta-analysis. Lancet. 2020; 395: 1973-1987.

5. Jessop ZM, Dobbs TD, Ali SR, et al. Personal protective equipment (PPE) for surgeons during COVID-19 pandemic: a systematic review of availability, usage, and rationing. Br J Surg. 2020. doi: 10.1002/bjs.11750.

Abilene Cirenia Escamilla Ortiz, MD

Editor, Cirujano General journal. orcid.org/0000-0001-5635-5845 